\title{
Combined Anti-PLGF and Anti-Endostatin Treatments Inhibit Ocular Hemangiomas
}

\author{
Hua Jiang Xinyi Wu Hong Wang Chao Huang Linna Zhang \\ Department of Ophthalmology, Qilu Hospital of Shandong University, Jinan, China
}

\section{Key Words}

Placental growth factor • Endostatin • Ocular hemangiomas • Ocular neovascularization

\begin{abstract}
Background/Aims: The degree of neovascularization determines the aggressiveness of ocular hemangiomas $(\mathrm{OH})$. So far, the anti-angiogenic treatments using either antagonists against vascular endothelial growth factor A (VEGF-A), or endostatin, do not always lead to satisfactory therapeutic outcome. Methods: We examined the VEGF receptor 1 (VEGFR1) levels in the $\mathrm{OH}$ specimen. We compared the effects of anti-PLGF, endostatin, as well as their combined treatments on the growth of $\mathrm{OH}$ in a mouse model, using bioluminescence imaging in living animals. We also examined vascularization by CD31 expression. Results: We detected higher VEGFR1 levels in the $\mathrm{OH}$, compared to paired normal tissue. Thus, we hypothesize that as a major ligand for VEGFR1, placental growth factor (PLGF) may also play a role in the neovascularization and tumorigenesis of $\mathrm{OH}$. In an implanted $\mathrm{OH}$ model in mice, we found that both anti-PLGF and endostatin significantly decreased $\mathrm{OH}$ growth as well as vascularization, while combined treatments had a significantly more pronounced effect. Conclusion: Our data suggest that combined anti-PLGF and endostatin may be a more effective therapy for inhibition of ocular vascularization and the tumor growth in $\mathrm{OH}$.
\end{abstract}

Copyright $\odot 2015$ S. Karger AG, Basel

\section{Introduction}

Hemangioma is a non-cancerous tumor caused by abnormal growth of blood vessels. Hemangiomas can occur anywhere on the body, but are most commonly found on the face and neck [1-3]. Ocular hemangiomas $(\mathrm{OH})$ can occur on the eyelids, on the conjunctiva or

Linna Zhang,

KARGER 125
Department of Ophthalmology, Qilu Hospital of Shandong University, 107 WenhuaXi Road, Jinan 250012 (China)

Tel. +8618560087117, Fax+8618560087117, E-Mail zhanglinna15@163.com 


\section{Cellular Physiology Cell Physiol Biochem 2015;36:930-936 \begin{tabular}{l|l|l}
\hline DOI: 10.1159/000430267 & C 2015 S. Karger AG, Basel
\end{tabular} and BiOChemistry Published online: June 12, $2015 \quad$ www.karger.com/cpb

in the orbit, and may interfere with the normal development of the eye and possibly lead to vision problems, including amblyopia and glaucoma [1-3] Ocular neovascularization may also occur in several ocular diseases, including proliferative diabetic retinopathy, neovascular age-related macular degeneration, and retinopathy of prematurity [4-7]. Together, all these diseases afflict persons in all stages of life from birth through late adulthood and account for most instances of legal blindness. Although anti-angiogenic treatments have proven therapeutic effects either with antagonist against vascular endothelial growth factor $\mathrm{A}$ (VEGF-A), or with endostatin, the therapeutic outcome in patients is not always satisfactory [4-12].

Angiogenesis and vascularization are promoted by angiogenic factors, including fibroblast growth factor, angiopoietins, matrix metalloproteinase (MMP), and VEGF family members, among which VEGF family is the most potent and important trigger for angiogenesis and vascularization [13]. The VEGF family is composed of six secreted proteins: VEGF-A, VEGF-B, VEGF-C, VEGF-D, VEGF-E and placental growth factor (PLGF) [13-18], which play critical roles in cancer growth and metastasis [19-25]. PLGF may play an important role in the pathological angiogenesis, in a coordinated way with other VEGF family members. However, the exact effect of PLGF on cancer neovascularization may be case-dependent. For example, PLGF produced by tumor and host cells has been reported to promote angiogenesis and tumor growth [26], or inhibit tumor angiogenesis by forming inactive VEGF/PLGF heterodimer [27]. There are three main subtypes of VEGF receptor (VEGFR), numbered 1, 2 and 3. Also, they may be membrane-bound or soluble, depending on alternative splicing. VEGF-A binds to both VEGFR1 and VEGFR2 [13]. VEGFR2 appears to mediate almost all of the known cellular responses to VEGF. The function of VEGFR1 is less well defined, although it is thought to modulate VEGFR2 signaling [13]. Interestingly, VEGFR1 is the unique binding receptor for PLGF. VEGFR3 mediates lymphangiogenesis in response to VEGF-C and VEGF-D [13]. Angiogenesis and vascularization are also inhibited by angiostatic factors, including soluble VEGFR1, endostatin, angiostatin, etc [13].

In the current study, we detected higher VEGFR1 levels in the OH, compared to paired normal tissue, leading to the hypothesis that as another major ligand for VEGFR1, PLGF may also play a role in the neovascularization and tumorigenesis of $\mathrm{OH}$. Thus we compared the effects of anti-PLGF, endostatin, and combined treatment on the growth of $\mathrm{OH}$ in vivo in a mouse model. We found that both anti-PLGF and endostatin significantly decreased $\mathrm{OH}$ growth, while combined treatment had a more pronounced effect. Moreover, the inhibition of $\mathrm{OH}$ growth was in parallel with the inhibition on vascularization.

\section{Materials and Methods}

\section{Cell lines and reagents}

C166 is a mouse endothelial cell line purchased from American Type Culture Collection (ATCC, Rockville, MD, USA), and was established from cells from F1 embryos obtained by mating a female NMRI/ GSF mouse with a male CD-1 mouse that was transgenic for the human fes (fps/fes) proto-oncogene [28]. C166 cells were cultured in Dulbecco's modified Eagle's media (DMEM) supplemented with 15\% fetal bovine serum (Invitrogen, Carlsbad, CA, USA). Anti-PLGF antisera and endostatin were purchased from Sigma-Aldrich (St. Louis, MO, USA).

\section{Transfection of C166 cells}

C166 cells were transfected with a plasmid carrying luciferase and GFP, connected by a 2A, under a CMV promoter. The small 2A peptide sequences, when cloned between genes, allow for efficient, stoichiometric production of discrete protein products within a single vector through a novel "cleavage" event within the 2A peptide sequence. Transfection was performed with Lipofectamine2000 (Invitrogen) transfection kit, according to the manufacturer's instructions. Successfully transduced C166 cells were selected by flow cytometry based on GFP.

\section{KARGER}




\section{Cellular Physiology Cell Physiol Biochem 2015;36:930-936 \begin{tabular}{|c|c|c|}
\hline DOI: 10.1159/000430267 & O 2015 S. Karger AG, Basel
\end{tabular} www.karger.com/cpb

\section{Mouse handling and in vivo bioluminescence imaging}

All mouse experiments were approved by the Institutional Animal Care and Use Committee at Shandong University (Animal Welfare Assurance). Surgeries were performed under ketamine/xylazine anesthesia, according the Principles of Laboratory Care. Twelve week-old male NOD/SCID mice were used in the current study. Five mice were analyzed in each experimental condition. Luciferase-expressing C166 cells $\left(10^{5}\right)$ were orthotopically implanted into the orbit of 12 week-old male NOD/SCID mice. After 4 weeks, the tumor growth was monitored and quantified by luminescence levels. Bioluminescence was measured with the IVIS imaging system (Xenogen Corp., Alameda, CA, USA). All of the images were taken 10 minutes after intraperitoneal injection of luciferin (Sigma-Aldrich) of $150 \mathrm{mg} / \mathrm{kg}$ body weight, as a 60 -second acquisition and 10 of binning. During image acquisition, mice were sedated continuously via inhalation of 3\% isoflurane. Image analysis and bioluminescent quantification was performed using Living Image software (Xenogen Corp).

\section{Western blot}

The protein was extracted from the resected $\mathrm{OH}$ from the patient specimen, or the resected $\mathrm{OH}$ from the mice, using RIPA buffer (Sigma-Aldrich). The supernatants were collected after centrifugation at $12000 \times \mathrm{g}$ at $4^{\circ} \mathrm{C}$ for $20 \mathrm{~min}$. Protein concentration was determined using BCA protein assay, and whole lysates were mixed with $4 \times$ SDS loading buffer $(125 \mathrm{mmol} / \mathrm{l}$ Tris- $\mathrm{HCl}, 4 \% \mathrm{SDS}, 20 \%$ glycerol, $100 \mathrm{mmol} / \mathrm{l} \mathrm{DTT}$, and $0.2 \%$ bromophenol blue) at a ratio of $1: 3$. Samples were heated at $100{ }^{\circ} \mathrm{C}$ for $5 \mathrm{~min}$ and were separated on SDSpolyacrylamide gels. The separated proteins were then transferred to a PVDF membrane. The membrane blots were first probed with a primary antibody. After incubation with horseradish peroxidase-conjugated second antibody, autoradiograms were prepared using the enhanced chemiluminescent system (Pierce, Rockford, IL, USA) to visualize the protein antigen. The signals were recorded using X-ray film. Primary antibodies were anti-VEGFR1 (Santa Cruz Biotechnology, Dallas, Texas, USA), anti-CD31 (Becton-Dickinson Biosciences, San Jose, CA, USA) and anti- $\beta$-actin (Cell Signaling, San Jose, CA, USA). $\beta$-actin was used as a protein loading control.

\section{$R T-q P C R$}

RNA was extracted from resected $\mathrm{OH}$ with RNeasy kit (Qiagen, Hilden, Germany) and used for cDNA synthesis. Quantitative PCR (RT-qPCR) were performed in duplicates with QuantiTect SYBR Green PCR Kit (Qiagen). Primers for CD31 and $\beta$-actin were purchased from Qiagen. Values of genes were normalized against $\beta$-actin and then compared to the control.

\section{Statistical analysis}

All statistical analyses were carried out using the SPSS 17.0 statistical software package. All data were statistically analyzed using one-way ANOVA with a Bonferoni Correction, followed by a Fisher's Exact Test for comparison between two groups. All values are depicted as mean \pm standard deviation from 5 individuals and are considered significant if $\mathrm{p}<0.05$.

\section{Results}

\section{High VEGFR1 was detected in $\mathrm{OH}$}

Since the degree of neovascularization determines the malignancy of $\mathrm{OH}$, and since present anti-angiogenesis treatments did not always achieve satisfactory results, we were prompted to figure out whether targeting angiogenic or anigostatic factors other than

Fig. 1. High level of VEGFR1 was detected in $\mathrm{OH}$. Representative Western blots for VEGFR1 in the resected $\mathrm{OH}$ samples and paired normal tissue (NT) from the same patient. $\beta$-actin was used as a protein loading control.

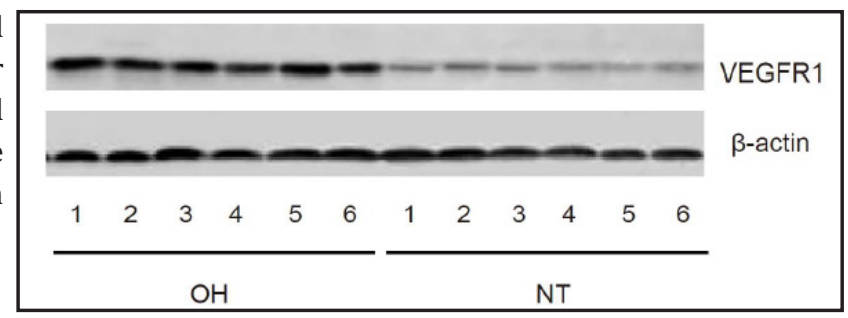


Fig. 2. Preparation of GFP and luciferase co-expressing C166 cells. (A) We transduced a mouse endothelial cell line, C166, with GFP and luciferase. (B) Successfully transduced cells (green rectangle) were isolated by flow cytometry, shown by a representative flow chart. (C) Purified green fluorescent cells in culture. All green cells also co-expressed luciferase, to allow detection in vivo after luciferin injection. Scale bar is $50 \mu \mathrm{m}$.
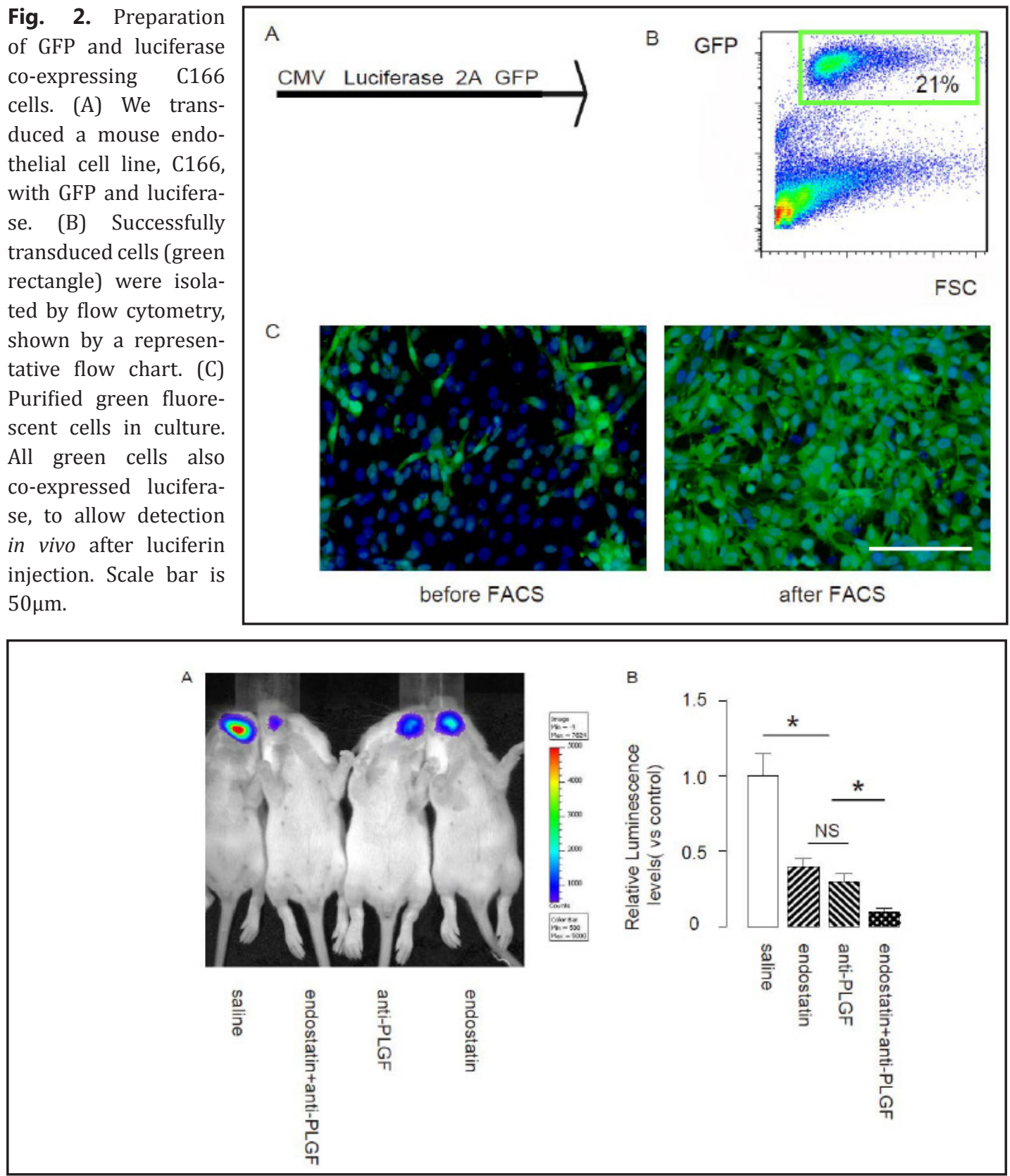

Fig. 3. Combined treatments with anti-PLGF and endostatin inhibited OH growth in vivo. We orthotopically implanted $10^{5}$ luciferase-expressing C166 cells into the orbit of 12 week-old male NOD/SCID mice. The mice received intraperitoneal injection with either control saline, or anti-PLGF alone, or endostatin alone, or combined anti-PLGF and endostatin, every other day till 4 weeks when the mice were monitored for tumor growth. (A-B) Bioluminescence was shown by representative images (A), and by quantification (B). ${ }^{*} \mathrm{p}<0.05$. NS: non-significant. $\mathrm{N}=5$.

VEGF-A and endostatin may improve the outcome of the anti-angiogenesis treatments. We analyzed the resected $\mathrm{OH}$ samples from the patients by Western blot, and compared to paired normal tissue (NT). We detected higher VEGFR1 levels in OH specimen (Fig. 1). VEGFR1 has two ligands, VEGF-A and PLGF. Specifically, VEGFR1 is the unique receptor for PLGF. We thus hypothesized that PLGF may also play a role in the neovascularization and tumorigenesis of $\mathrm{OH}$. 
Fig. 4. Combined treatment with anti-PLGF and endostatin inhibited ocular neovascularization. (A-B) The vessel density in $\mathrm{OH}$ from the mice was quantified by CD31 transcript levels (A) and by CD31 protein, shown by representative Western blots (B). $\quad * \mathrm{p}<0.05 . \quad$ NS: non-significant. $\mathrm{N}=5$.

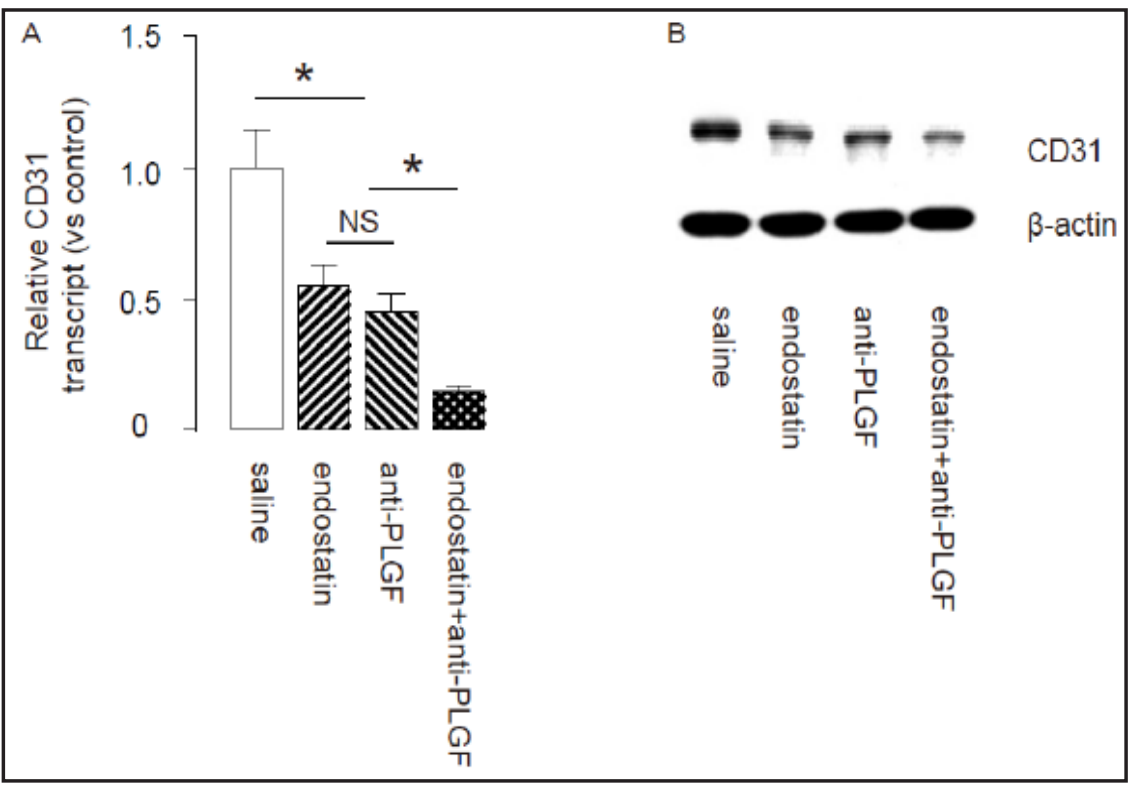

Preparation of C166 cells labeled with GFP and luciferase

Thus we aimed to compare the effects of anti-PLGF, endostatin and combined treatment on the growth of $\mathrm{OH}$ in vivo in a mouse model. First, we transduced a mouse endothelial cell line C166 with GFP and luciferase for purification and in vivo tracing, respectively (Fig. 2A). Successfully transduced cells were selected by flow cytometry (Fig. 2B), showing high green fluorescence in culture. These green cells also expressed luciferase, to allow detection in vivo after luciferin injection.

Combined treatment with anti-PLGF and endostatin inhibited OH growth in vivo

Then we orthotopically implanted $10^{5}$ luciferase-expressing C166 cells into the orbit of 12 week-old male NOD/SCID mice. The mice received intraperitoneal injection with either control saline, or anti-PLGF alone, or endostatin alone, or combined anti-PLGF and endostatin, every other day till 4 weeks when the mice were monitored for tumor growth.

We found that both anti-PLGF and endostatin alone significantly decreased $\mathrm{OH}$ growth, while combined treatment had a significantly more pronounced effect (Fig. 3A-B). These data suggest that endostatin and anti-PLGF have independent anti-tumor effects and the combination has an enhanced effect than each.

Combined treatment with anti-PLGF and endostatin inhibited ocular neovascularization

Moreover, when we analyzed the vessel density in $\mathrm{OH}$ from these mice by quantification of CD31 at both transcription level (Fig. 4A) and protein level (Fig. 4B), we found that the inhibition of $\mathrm{OH}$ growth was in parallel with the inhibition on vascularization. CD31 is a specific marker for endothelial cells. These data suggest that combined anti-PLGF and endostatin may be more effective therapy for inhibition of ocular vascularization. This antiangiogenesis effect in $\mathrm{OH}$ results in inhibition of the tumor growth.

\section{Discussion}

Ocular neovascularization occurs in ocular diseases, including proliferative diabetic retinopathy, neovascular age-related macular degeneration, retinopathy of prematurity, and specifically, $\mathrm{OH}[1,2,4-7]$. Although anti-angiogenesis treatments have proven therapeutic effects with either antagonist against VEGF-A, or with endostatin, the therapeutic outcome in the patients is not always satisfactory [4-7].

\section{KARGER}




\section{Cellular Physiology Cell Physiol Biochem 2015;36:930-936 \begin{tabular}{c|c|} 
DOI: 10.1159/000430267 & O 2015 S. Karger AG, Basel \\
\hline
\end{tabular} www.karger.com/cpb \\ Jiang et al.: Inhibition of $\mathrm{OH}$ by anti-PLGF and Endostatin}

VEGF family is the most potent and important trigger of angiogenesis and vascularization [13]. The VEGF family is composed of six secreted proteins, including VEGF-A and PLGF [13-15]. PLGF plays an important role in the pathological angiogenesis. Among the three VEGFRs, VEGFR1 binds to both VEGF-A and PLGF and is the only receptor that PLGF binds. In the current study, we detected high level of VEGFR1 in the OH from the patients, leading to the hypothesis that PLGF may also play a role in the neovascularization and tumorigenesis of $\mathrm{OH}$.

Thus we compared the effects of anti-PLGF, endostatin, and combined treatment on the growth of $\mathrm{OH}$ in vivo in a mouse model. We found that both anti-PLGF and endostatin significantly decreased $\mathrm{OH}$ growth, while combined treatment had a more pronounced effect. These data suggest that both PLGF and endostatin regulate the angiogenesis of $\mathrm{OH}$, but they may have different regulation pathways. We further found that the inhibition of $\mathrm{OH}$ growth was in parallel with the inhibition in vascularization, suggesting that inhibition of $\mathrm{OH}$ growth may result from the inhibition of the growth of endothelial cells and angiogenesis. Taken together, our data suggest that combined anti-PLGF and endostatin may be more effective therapy for inhibition of ocular vascularization, and specifically in $\mathrm{OH}$, the tumor growth. Our result thus sheds insight on a new strategy to control the ocular neovascularization and treatment of related diseased through targeting both PLGF and endostatin.

\section{Disclosure Statement}

The authors have declared that no competing interests exist.

\section{Acknowledgement}

This work was financially sported by Jinan Youth Technology Star Plan (20120133) and Shandong Excellent Youth Scientist Research Fund (BS2013YY014).

\section{Reference}

1 Dubois J, Milot J, Jaeger BI, McCuaig C, Rousseau E, Powell J: Orbit and eyelid hemangiomas: Is there a relationship between location and ocular problems? Journal of the American Academy of Dermatology 2006;55:614-619.

2 Hiles DA, Pilchard WA: Corticosteroid control of neonatal hemangiomas of the orbit and ocular adnexa. Am J Ophthalmol 1971;71:1003-1008.

3 Li YJ, Jiang Q, Cao GF, Yao J, Yan B: Repertoires of autophagy in the pathogenesis of ocular diseases. Cell Physiol Biochem 2015;35:1663-1676.

4 Campochiaro PA: Ocular neovascularization. J Mol Med (Berl) 2013;91:311-321.

5 Cai X, Sezate SA, McGinnis JF: Neovascularization: Ocular diseases, animal models and therapies. Adv Exp Med Biol 2012;723:245-252.

6 Bradley J, Ju M, Robinson GS: Combination therapy for the treatment of ocular neovascularization. Angiogenesis 2007;10:141-148.

7 Campochiaro PA: Gene therapy for ocular neovascularization. Curr Gene Ther 2007;7:25-33.

8 Huo X, Li Y, Jiang Y, Sun X, Gu L, Guo W, Sun D: Inhibition of ocular neovascularization by co-inhibition of vegf-a and plgf. Cell Physiol Biochem 2015;35:1787-1796.

9 Kim S, Oh SJ, Lee J, Han J, Jeon M, Jung T, Lee SK, Bae SY, Kim J, Gil WH, Kim SW, Lee JE, Nam SJ: Berberine suppresses tpa-induced fibronectin expression through the inhibition of vegf secretion in breast cancer cells. Cell Physiol Biochem 2013;32:1541-1550. 


\section{Cellular Physiology Cell Physiol Biochem 2015;36:930-936

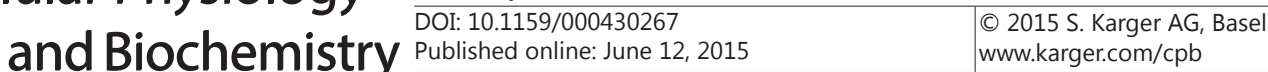 \\ Jiang et al.: Inhibition of $\mathrm{OH}$ by anti-PLGF and Endostatin}

10 Zhu X, Er K, Mao C, Yan Q, Xu H, Zhang Y, Zhu J, Cui F, Zhao W, Shi H: Mir-203 suppresses tumor growth and angiogenesis by targeting vegfa in cervical cancer. Cell Physiol Biochem 2013;32:64-73.

11 Xu CW, Zhang TP, Wang HX, Yang H, Li HH: Chip enhances angiogenesis and restores cardiac function after infarction in transgenic mice. Cell Physiol Biochem 2013;31:199-208.

12 Zhang J, Wu Y, Chen A, Zhao Q: Mesenchymal stem cells promote cardiac muscle repair via enhanced neovascularization. Cell Physiol Biochem 2015;35:1219-1229.

13 Ferrara N, Gerber HP, LeCouter J: The biology of vegf and its receptors. Nat Med 2003;9:669-676.

14 Xiao X, Prasadan K, Guo P, El-Gohary Y, Fischbach S, Wiersch J, Gaffar I, Shiota C, Gittes GK: Pancreatic duct cells as a source of vegf in mice. Diabetologia 2014;57:991-1000.

15 Xiao X, Guo P, Chen Z, El-Gohary Y, Wiersch J, Gaffar I, Prasadan K, Shiota C, Gittes GK: Hypoglycemia reduces vascular endothelial growth factor a production by pancreatic beta cells as a regulator of beta cell mass. J Biol Chem 2013;288:8636-8646.

16 Zhang J, Wu Y, Chen A, Zhao Q: Mesenchymal stem cells promote cardiac muscle repair via enhanced neovascularization. Cell Physiol Biochem 2015;35:1219-1229.

17 Jia RZ, Ding GC, Gu CM, Huang T, Rui C, Wang YX, Lu Q: Cdx2 enhances htr-8/svneo trophoblast cell invasion by altering the expression of matrix metalloproteinases. Cell Physiol Biochem 2014;34:628-636.

18 Nagao H, Nakajima K, Niisato N, Hirota R, Bando H, Sakaguchi H, Hisa Y, Marunaka Y: K(+)-cl(-) cotransporter 1 (kcc1) negatively regulates ngf-induced neurite outgrowth in pc12 cells. Cell Physiol Biochem 2012;30:538-551.

19 Ma J, Sawai H, Ochi N, Matsuo Y, Xu D, Yasuda A, Takahashi H, Wakasugi T, Takeyama H: Pten regulates angiogenesis through pi3k/akt/vegf signaling pathway in human pancreatic cancer cells. Mol Cell Biochem 2009;331:161-171.

20 Cabebe E, Fisher GA: Clinical trials of vegf receptor tyrosine kinase inhibitors in pancreatic cancer. Expert Opin Investig Drugs 2007;16:467-476.

21 Hotz HG, Hines OJ, Masood R, Hotz B, Foitzik T, Buhr HJ, Gill PS, Reber HA: Vegf antisense therapy inhibits tumor growth and improves survival in experimental pancreatic cancer. Surgery 2005;137:192-199.

22 Chen Y, Jiang T, Mao A, Xu J: Esophageal cancer stem cells express plgf to increase cancer invasion through mmp9 activation. Tumour Biol 2014;35:12749-12755.

23 Zhou X, Qi Y: Plgf inhibition impairs metastasis of larynx carcinoma through mmp3 downregulation. Tumour Biol 2014;35:9381-9386.

24 Chen B, Zhang C, Dong P, Guo Y, Mu N: Molecular regulation of cervical cancer growth and invasion by vegfa. Tumour Biol 2014;35:11587-11593.

25 Mao D, Zhang Y, Lu H, Zhang H: Molecular basis underlying inhibition of metastasis of gastric cancer by anti-vegfa treatment. Tumour Biol 2014;35:8217-8223.

26 Carmeliet P, Moons L, Luttun A, Vincenti V, Compernolle V, De Mol M, Wu Y, Bono F, Devy L, Beck H, Scholz D, Acker T, DiPalma T, Dewerchin M, Noel A, Stalmans I, Barra A, Blacher S, Vandendriessche T, Ponten A, Eriksson U, Plate KH, Foidart JM, Schaper W, Charnock-Jones DS, Hicklin DJ, Herbert JM, Collen D, Persico MG: Synergism between vascular endothelial growth factor and placental growth factor contributes to angiogenesis and plasma extravasation in pathological conditions. Nat Med 2001;7:575-583.

27 Eriksson A, Cao R, Pawliuk R, Berg SM, Tsang M, Zhou D, Fleet C, Tritsaris K, Dissing S, Leboulch P, Cao Y: Placenta growth factor-1 antagonizes vegf-induced angiogenesis and tumor growth by the formation of functionally inactive plgf-1/vegf heterodimers. Cancer Cell 2002;1:99-108.

28 Wang SJ, Greer P, Auerbach R: Isolation and propagation of yolk-sac-derived endothelial cells from a hypervascular transgenic mouse expressing a gain-of-function fps/fes proto-oncogene. In Vitro Cell Dev Biol Anim 1996;32:292-299. 